\title{
As Escolas Públicas Paulistas da Primeira República e seus Arquitetos
}

\author{
Silvia Ferreira Santos Wolff
}

Discute-se a origem da arquitetura escolar oficial em Sāo Paulo e seu processo evolutivo ao longo da Primeira República. Busca-se refletir sobre os aspectos criativos desta arquitetura mediante a análise das constribuiçōes específicas de alguns arquitetos, cujas obras parecem contrapor-se à arquitetura eclética vista como uma produção acrítica e resultante de imitaçōes irrefletidas de exemplos estrangeiros.

This paper studies the origins of the architecture of the public school buildings in the state of São Paulo, as well of its development and changes since the last decade of the 19th century trough the twenties during the so-called "First Republic" The creative features of this this architecture are specially emphasized and an alalysis is made of the specific contributions of some architects, whose works seem to counteract the positions of those who consider the eclectic architecture as a result of no criticism and of thoughtless copies of foreign examples.
Artigo elaborado com base na Dissertaçāo de Mestrado "Espaço e educaçāo: os primeiros passos da arquitetura das escolas públicas paulistas", apresentada em julho de 1992. Orientador: Prof. Dr. Carlos Alberto Cerqueira Lemos. 


\section{Introdução}

Após um período no final do Império em que as iniciativas oficiais esporádicas de finalidade educacional resultaram em alguns poucos edifícios, será na República que se investirá em educação e em arquitetura escolar de modo efetivo. Mesmo sob a nova ordem política, porém, o investimento ocorrerá de forma desigual em cada Estado da Federação e, neste aspecto, São Paulo destaca-se como um estado pioneiro e empreendedor. Deste empenho paulista resultarāo planos pedagógicos e uma arquitetura de características marcantes.

A arquitetura pioneira das escolas paulistas é produto de um momento em que o país modernizava-se com rapidez. Essas transformaçōes passavam não apenas pela alteração da ordem política, mas também pela renovação cultural e pelo recrudescimento das relaçōes de intercâmbio entre o Brasil e as nações hegemônicas do final do séc. X|X.

Neste quadro não são poucas as trocas entre o país e o mundo exterior, e a arquitetura entāo produzida as expõem com clareza. Serāo substantivas as influências aqui exercidas pela arquitetura internacional, cujo centro difusor principal era então a Academia da École des Beaux Arts de Paris. No Brasil, as novidades eram promovidas por profissionais brasileiros do ramo da construção formados no exterior, por estrangeiros que para cá se deslocavam, pelo crescente circuito de veiculaçāo de informações através de publicações especializadas e pela facilidade de importação de materiais e modelos.

Dentro deste quadro, a questão que se coloca é se teria sido esta importação de modelos acrítica e literal. A historiografia tradicional produzida a partir de uma perspectiva critica moldada sob a ótica da arquitetura moderna costuma afirmar que sim. Desta forma, a produção eclética é generalizadamente classificada como uma arquitetura resultante de imitaçōes ignorantes de modelos estrangeiros, manifestações de terrível gosto fruto de licenciosidade estilísti$\mathrm{ca}^{1} \mathrm{~A}$ arquitetura escolar paulista da Primeira República parece dizer que não é bem assim.

Em primeiro lugar porque a realidade de simplificações e empobrecimento dos programas administrativos no país, em relação a modelos de outras realidades, implicavam também modificações dos planos funcionais e, conseqüentemente, da arquitetura. Mas, nāo apenas, os próprios ritmos da consolidação de uma arquitetura paulista passaram por motivaçōes específicas que exigiram gestos criativos de seus autores e, seguramente, imprimiram-lhe uma feiçāo particular.

\section{A Evolução da Arquitetura Escolar Paulista em seu Período Pioneiro}

A concretização das políticas governamentais em prédios escolares, na Primeira República em São Paulo, aconteceu através do que poderia ser chamado de surtos de construções. O primeiro deles segue-se às primeiras medidas legais e de planejamento do recém-implantado governo estadual republicano. Iniciase, em 1890, com o projeto da sede para a Escola Normal da Praça da República, depois chamada Caetano de Campos em homenagem ao educador

(1) A respeito da visâo tradicıonal da hıstorıografia brasileıra sobre o Eclelımo cf WEIMER, Gunter Os anos obscuros Pós: Revista do Programa de Pós-graduaçáo em Arquitelura e Urbanismo da FAUUSP, Sáo Paulo, n 2. p 85-96, dezembro 1992 que a dirigia naquele momento. A esta segue-se uma série de projetos e obras de estabelecimentos modelares para ensino básico.

Estes podem ser classificados como os primeiros passos da arquitetura escolar oficial paulista. Fruto de muita vontade política e de rudimentar estrutura 
técnica e administrativa, é uma arquitetura desbravadora, pioneira. Uma arquitetura caracterizada pela experimentação e por tentativas que têm por conseqüência algumas fórmulas quase invariáveis de se enfrentar construções escolares. São típicos dessa fase os edifícios que, em dois pavimentos, buscam equacionar espacialmente uma escola funcional e adequada. $E$, também, projetos que, com o auxílio de alegorias esculpidas ou em baixo relevo, situadas nas fachadas principais concebidas de acordo com um repertório estético em voga em âmbito internacional, tentam delinear a imagem imponente de uma escola pública.

O segundo momento, prefigurado nas soluções arquitetônicas do fim desse período, já se equaciona, sobretudo, em prédios escolares térreos. A preocupação maior neste momento, em que as metas visavam à disseminação do ensino básico por toda a rede urbana, que se formava pelo Interior do estado, era a de que os prédios escolares fossem corretos, mas baratos, facilmente elaborados e que atendessem numericamente à crescente demanda.

Os prédios desta fase resultaram de uma fonte substancial de recursos liberados no início dos anos 10. Uma dotação orçamentária especifica, durante a presidência do Estado de Albuquerque Lins, implicou a construção maciça de prédios escolares.

Para a concepção dos prédios escolares, provenientes desse esforço foi necessário o aumento de pessoal técnico do serviço dedicado às obras públicas paulistas e a consecução de soluções rapidamente exeqüiveis.

Após este surto de grande quantidade de escolas primárias, projetadas e construídas logo no início da década de 10, a arquitetura escolar prosseguiu em ritmo mais moroso. Baseou-se então em procedimentos operacionais e conquistas arquitetônicas incorporados no período anterior de forma mais ou menos inalterada até praticamente o final da década de 20, quando, sobretudo em termos estilísticos, prenunciam-se as simplificações que seriam introduzidas com o despojamento da arquitetura moderna.

Estudando com detalhe a arquitetura escolar produzida durante a Primeira República em São Paulo vão se estabelecendo as sutís diferenças de cada momento. Estabelecem-se distinçōes e a seqüência de desenvolvimento de um processo evolutivo que, se observado com menor atenção, não seria identificado. O conjunto das escolas paulistas seria assim, eventualmente agrupado como um todo eclético homogêneo. Com atenção para o detalhe é possivel perceber em cada manifestação a resposta a exigências especificas da época e do programa para o qual foram produzidas, e, também verificar seu processo de transformação. São identificáveis, ainda, as distintas contribuiçōes dos arquitetos envolvidos nesse trabalho de pesquisa por uma arquitetura escolar ideal para São Paulo naquele primeiro momento.

\section{Arquitetos de Escolas Públicas}

Quais foram estes arquitetos, quem produziu a arquitetura das escolas públicas paulistas, quem formulou a identidade dos espaços funcionais que se fixaram na memória de gerações de paulistas como o "Grupo" a "Escola Normal" o "Ginásio do Estado"?

Toda a arquitetura escolar oficial paulista da Primeira República foi realizada sob a coordenação de um órgão da administração pública responsável pela realização das obras públicas paulistas por mais de um século. 
Quando se iniciou a atividade de construir escolas em 1890, esta repartiçāo pública chamava-se Superintendência de Obras Públicas e contava com pouquíssimos profissionais. No final da década de 20, vários arquitetos já tinham passado por lá e deixado sua contribuição para a arquitetura oficial paulista.

Alguns tiveram seus nomes consagrados como Ramos de Azevedo ou Victor Dubugras, outros permaneceram na obscuridade a que o exercício profissional no serviço público ou a passagem do tempo os relegou, como José van Humbeeck, Manuel Sabater e Carlos Rosencrantz.

Neste espaço, serão abordados apenas estes citados, cujos trabalhos tiveram particular importância para a arquitetura das escolas públicas paulistas. Entre o de tantos outros anônimos, o trabalho destes profissionais teve o significado de proporcionar soluçōes prontamente absorvidas. criando condições para o desenvolvimento de uma tipologia arquitetônica de nenhuma tradição local anterior.

\section{Ramos de Azevedo e as Escolas Públicas}

Ramos de Azevedo já vinha afirmando seu papel de arquiteto de obras públicas desde o final do Império. Sua passagem por Campinas, quando do retorno de seu período de estudos na Bélgica, havia sido marcada por sua capacidade de conclusāo das obras da Catedral, antes desenvolvidas com muita lentidão.

No final da década de 1880, esse arquiteto começou a trabalhar em Sāo Paulo. Com suas obras destinadas a abrigar secretarias de governo, no Pátio do Colegio. Ramos de Azevedo inscreve as marcas da monumentalidade e plástica modernas na cidade em transformaçāo. Os prédios concebidos dentro de uma nova estética monumental foram construidos com a técnica de alvenaria de tijolos e compostos com ornamentos neoclássicos.

Essa estética, inovadora na provincia paulista e seu divulgador. sem dúvida, respondiam bem às expectativas dos governantes, quando estes iniciaram a sua ação republicana, que implicava na construção de prédios para abrigar as novas estruturas e funçōes administrativas. Ramos de Azevedo é contemplado ao longo de sua carreira, mas especialmente no final do séc. XIX, por uma rara reverência por parte dos órgãos públicos. Seu escritório assina projetos, administra obras, obtem isenção de impostos alfandegários na compra de materiais importados para a realização de um sem número de projetos públicos. Tarefas que obtém, aparentemente, sem inscrever-se em concorrèncias publicas.

Fez parte do espírito de reconhecimento da capacidade de Ramos de Azevedo de criar belos prédios e como o arquiteto natural para os novos projetos públicos de maior evidência, sua participação no projeto da sede nova para a Escola Normal de Sāo Paulo. No desenvolvimento do projeto republicano de educação foi vista como necessária a formação adequada de professores e para tanto urgiam instalaçōes precisas em um prédio exemplar.

A trajetória da participação direta de Ramos de Azevedo na concepção de escolas públicas inicia-se, entāo, pelo desenvolvimento e construção deste projeto e prossegue por uma série de outros ao longo dos anos.

A primeira idéia sobre a qual se organiza o desenvolvimento do projeto da Escola Normal, concluído por Ramos de Azevedo, era de autoria do engenheiro Antonio Francisco de Paula Souza, engenheiro de sólida e erudita formação na Suiça e na Alemanha. 
Em sua idéia original Paula Souza seguramente fez valer sua formação em escolas da Europa germânica, assim como no desenvolvimento do projeto, seu colega, Ramos de Azevedo, sua formação na Bélgica flamenga. O projeto da nova Escola Normal de São Paulo afigura-se desta maneira como uma adaptação desta bagagem cultural ao gosto local que vinha se conformando, sob a influência do próprio Ramos de Azevedo e sob as liçōes de arquitetos italianos que chegavam a São Paulo. Victor Dubugras, por sua vez, colaborador de Ramos de Azevedo neste momento deve ter contribuído com a experiência de sua formação na Argentina. O mestre italiano de Dubugras, o arquiteto Francisco Tamburini, projetara inclusive a Escola Normal Portenha.

No projeto da Escola Normal paulistana, Ramos de Azevedo utilizou elementos ornamentais do vocabulário clássico, criando uma composição que é presidida por uma monumentalidade conferida pela harmonia, pela simetria e pela superposição de ordens em seu embasamento e dois pavimentos. Para a majestade
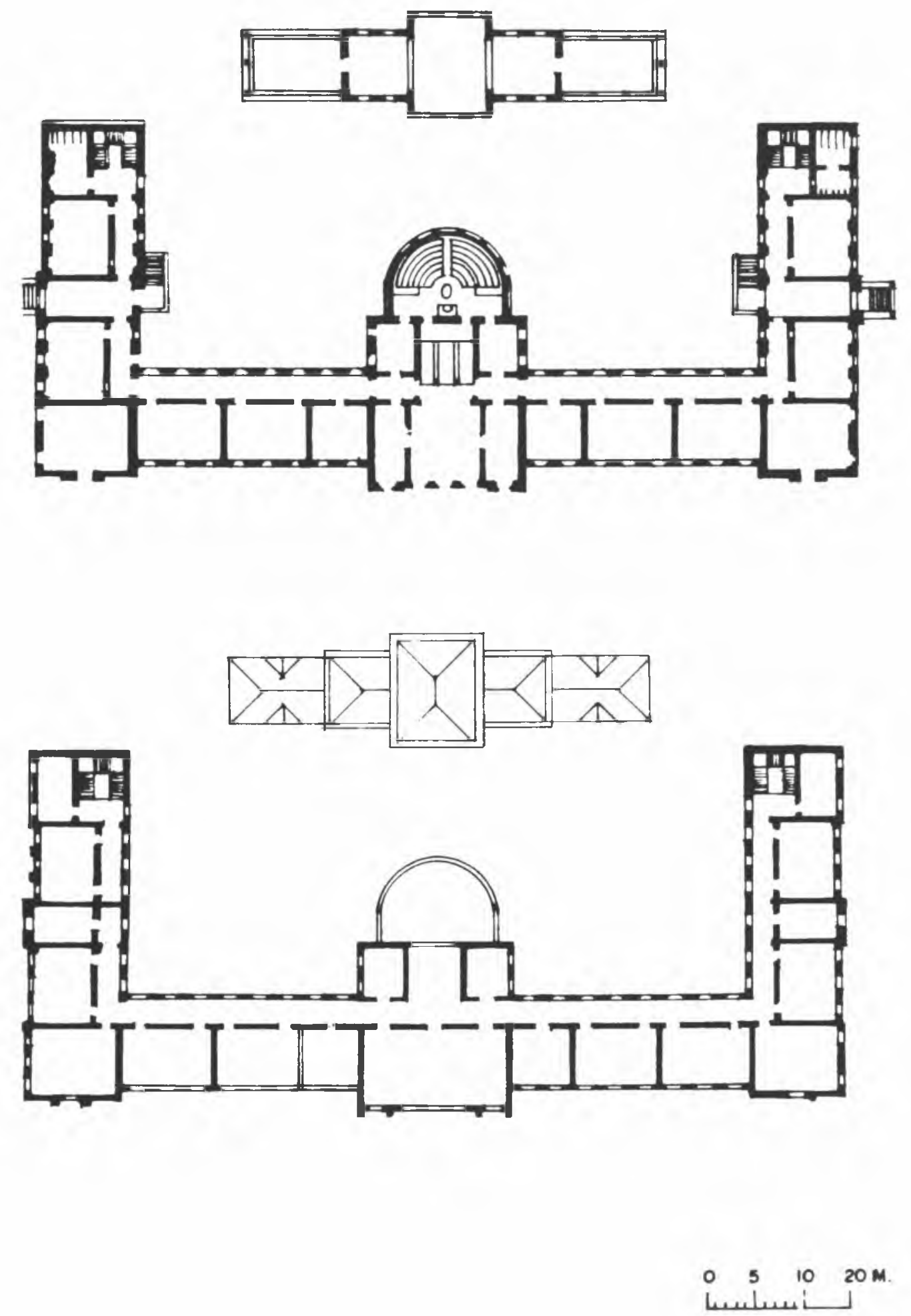

Foto 1

Escola Normal

Foto: fornecida pela autora

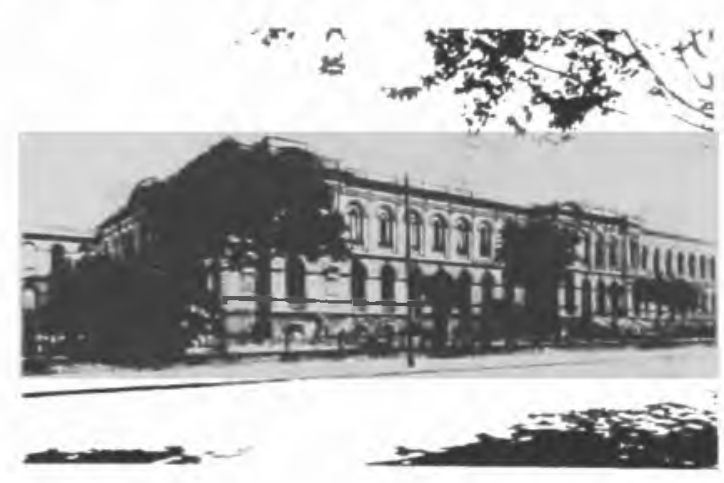

FAUUSP 


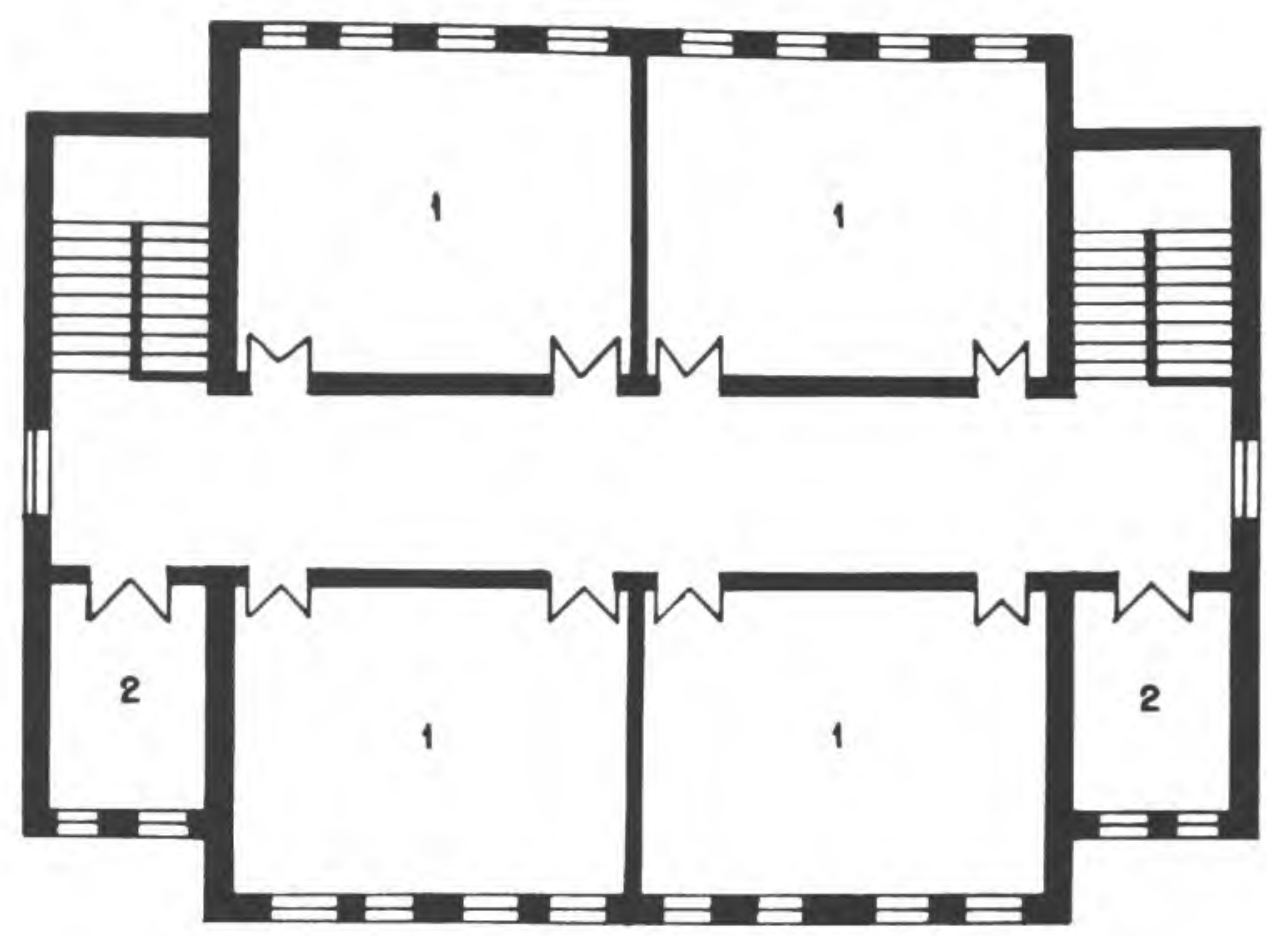

Foto 2

Grupo Escolar de Campinas

Foto: fornecida pela autora
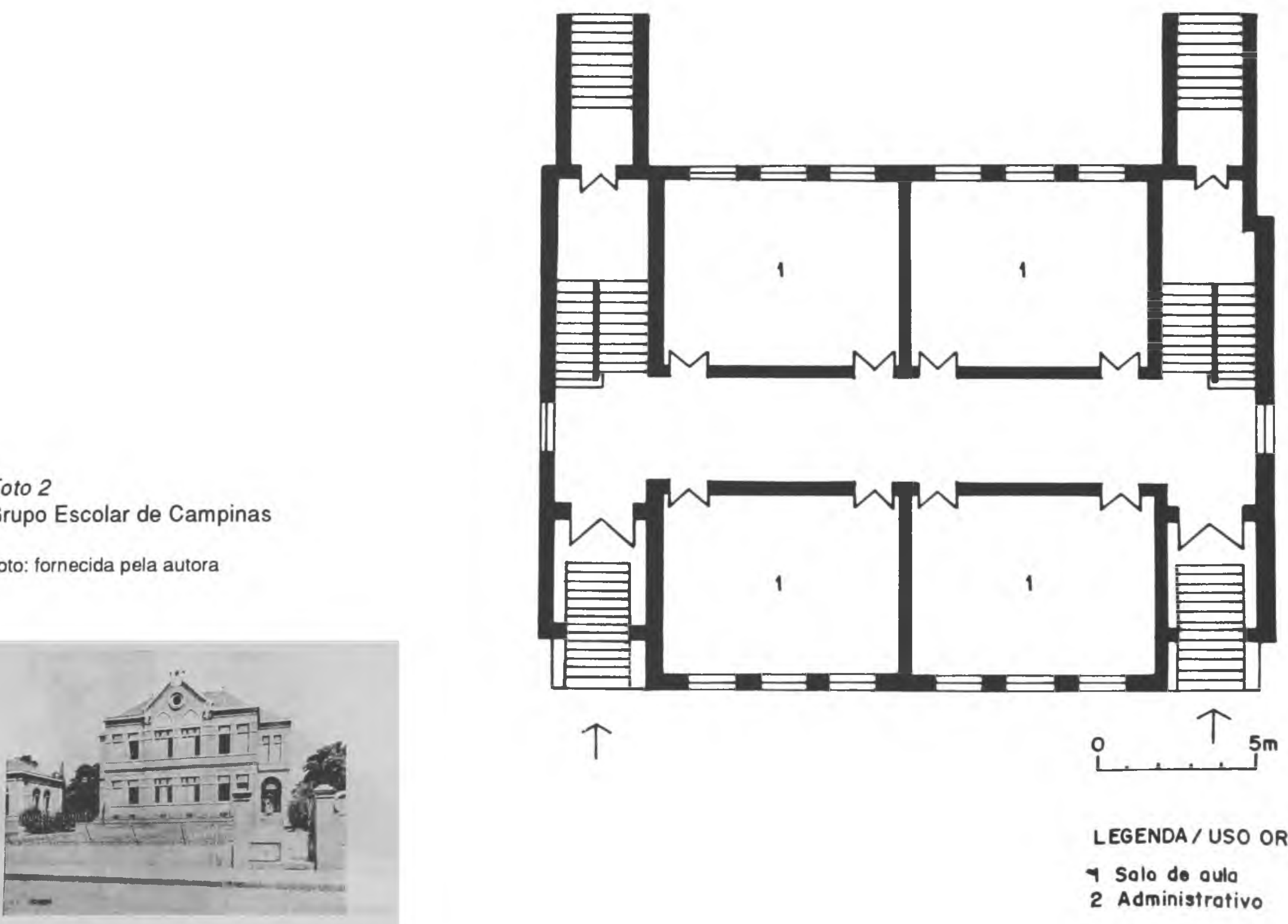

LEGENDA / USO ORIGINAL

Y Solo de oulo

2 Administrotivo 
do conjunto contribuía sua implantaçāo isolada num terreno livre de vizinhos próximos e que se confrontava com um largo, local da futura praça da República. (Muito posteriormente o prédio foi ampliado de dois para três pavimentos.)

As plantas do prédio denotam uma intenção de organizar com racionalidade e clareza salas de aula em torno de eixo de circulaçāo em forma de um grande "U" Esta organização espacial é coerente com a tipologia de estabelecimentos de ensino que vinha se firmando na Europa. Um acesso grandioso centralizado em uma ala de cujas extremidades nascem braços perpendiculares, neste caso nāo muito longos. Um anfiteatro localizado em frente à entrada, apenas sugere uma subdivisão no espaço circunscrito pelas três alas.

O novo prédio da Escola Normal nada ficava a dever aos seus modelos de inspiraçāo europeus, mas passava por uma adequaçāo à escala local. Era racional e moderno em seu funcionamento e estilisticamente adequado, segundo a visāo da época - monumental, eloqüente, mas nāo excessivo.

Todos os conceitos pedagógicos que se pretendia implantar estavam contemplados nas espaçosas instalaçōes que, em sua aparência, seguiam bem os ditames preconizados nos manuais e revistas de arquitetura contemporâneos, mas nāo imitavam nenhum modelo particular. Os "dogmas estilísticos" entāo divulgados diziam que a arquitetura pública era feita para durar, para expressar os ideais de nobreza, expressar a dignidade das naçōes e que tais objetivos só seriam alcançados se a arquitetura pública fosse composta segundo os ideais do Classicismo. Para os prédios oficiais não eram toleradas fantasias estilísticas ${ }^{2}$

A retórica do edifício da Escola Normal de São Paulo apoiou-se, assim, mais em sua unidade, sua massa majestosa do que em variedade e profusão ornamental. O prédio da nova Escola Normal era desta forma um edifício novo, grande, funcional e digno. Pronto para desempenhar seu papel de propagador da idéia de educaçāo de seus idealizadores.

É importante verificar que, ainda que para uma visão atual o prédio pareça excessivamente rebuscado, nāo era esta a intenção fundamental de seu projeto. E mais, o edifício não resultava da imitação literal de algum modelo estrangeiro, mas sim era fruto de uma concepçāo arquitetônica que fazia parte de um pensamento, cujas origens residiam na Europa.

\section{A Gênese dos Grupos Escolares}

Entre as contribuiçōes notáveis que se pode imputar à participaçāo de Ramos de Azevedo, no início da arquitetura escolar paulista, está o projeto para o Grupo Escolar de Campinas. Este projeto funcionou como a planta-matriz para quase todos os grupos escolares construídos no interior do estado na virada do século, em sua maioria desenvolvidos por Victor Dubugras.

O projeto do Grupo Escolar de Campinas, visto aqui como um protótipo, limitou-se a agrupar, sobre um porão que se amoldava ao terreno, uma construção de dois pavimentos de volume contido. O programa restringia-se a dois ambientes administrativos e oito salas de aula (quatro por andar), dispostas duas a duas ao longo de um eixo de circulaçāo central, paralelo à fachada principal. Os sanitários, numa época em que apenas se iniciavam as instalaçōes de redes públicas de água e esgoto nas cidades do interior, isolavam-se em construçōes separadas nos fundos dos terrenos, providas de fossas e consagradas por geraçōes de alunos como as "casinhas"
(2) A resperio da opçáo estilística da arquitetura de acordo com sua funçáo cf César DALY, L'ar chitecture privée au XIXmo siecle, sous Napo. león III: nouvelles malsons de Paris et des environs Paris Ducher 1872 
Será uma marca comum, sem exceção, a todos os primeiros prédios de grupos escolares, serem construções resolvidas em dois pavimentos. Um eixo de simetria perpendicular à fachada dividia o terreno, inclusive nos recreios posteriores, destinando-se cada metade a alunos e alunas. No interior do prédio, a separação das alas feminina e masculina se efetivava nos pavimentos.

Esboça-se, nesses projetos, a utilização dos embasamentos do porão como elementos de acomodaçāo do esquema invariável a terrenos distintos. Esse recurso levado ao limite mais tarde, permitirá a concepção de escolas em série, exigindo apenas como detalhamento individual de cada projeto, o levantamento topográfico de cada terreno e a adequação dos modelos padronizados a essas condições especificas, com grande economia de desenhos. Nesse primeiro momento, porém. a busca de variação na composição das fachadas ainda fazia com que cada projeto fosse realizado individualmente.

Ramos de Azevedo. em seus projetos numa continuidade da obra pública. que iniciara no Pátio do Colégio. cria seus espaços privilegiando fachadas de composição neoclássica, filiadas a sua formação acadêmica européia. Será também vinculada a essas formas acadêmicas a arquitetura que desenvolve na mesma época para a Escola Politécnica e para o Liceu de Artes e Ofícios. O clássico comparecia como uma síntese arquetípica da tradição greco-latina, da cultura européia, da civilizaçāo redentora do atraso que se desejava superar nesses "templos do saber"

Ramos de Azevedo está inequivocamente vinculado à gênese do pensamento da arquitetura escolar pública paulista. Seja por ter desenvolvido e efetivado idéias suas ou precedentes, como é o caso da Escola Normal da Capital, marco inicial desse pensamento: seja por idealizar os projetos pioneiros, a partir dos quais desenvolveram-se todos os prédios escolares construídos nos primeiros 10 anos de investimentos nesse sentido em Sāo Paulo.

\section{Victor Dubugras e os Grupos Escolares}

Não foi demorada a passagem de Victor Dubugras pela Superintendência de Obras Públicas, mas foi marcante. Em aproximadamente quatro anos de atividade junto ao serviço público (entre 1895-1898) esteve à frente da realizaçāo de projetos de escolas, fóruns e cadeias inteiramente novos, além de adaptações e complementações de outros tantos espalhados pelo interior do estado.

$\mathrm{Na}$ ideação dos primeiros projetos das escolas públicas que concebeu em 1895. Victor Dubugras inspirou-se no projeto da Escola de Campinas, assinado por Ramos de Azevedo - o esquema de escola de oito salas de aula, distribuídas em dois pavimentos de plantas idênticas e rebatidas. Alterando pouco este esquema espacial propôs novos desenhos para as fachadas de quatro prédios escolares.

Mas esse aspecto de recriação arquitetônica não diminuiu o sentido de pesquisa e experimentação que, individualmente, conferiu a seu trabalho no desenvolvimento de projetos públicos. Para cada uma destas escolas citadas criou uma fachada diferente, na qual variava a disposiçāo e desenho das envasaduras, os arremates das molduras de vãos e platibandas, o uso decorativo dos revestimentos - tijolos aparentes ou massa imitando pedras, enfim a própria opção estilística. Suas fontes de inspiração traziam o sabor das apropriações românticas da arquitetura medieval, realizadas no séc. XIX - vãos ogivais, rosáceas, seteiras, materiais aparentes, platibandas recortadas com ameias. 
É claro o impulso criativo de Victor Dubugras nas obras que assina, logo a seguir a estes planos que adaptou a partir da proposta de Ramos de Azevedo, em projetos exclusivamente seus, realizados na superintendência. Elaborava com capricho seus desenhos em projetos completos nos quais os detalhes ornamentais eram alvo de atenção demorada. Nesses projetos se lançou como autor que buscava sua identidade profissional. Nāo se apoiou nos modelos estilísticos acadêmicos consagrados, que regiam as composiçōes dos arquitetos para quem prestara serviços até então. Buscou renovação e autonomia. O historicismo medievalista que utilizou em suas criaçōes, ainda que enfatizando aspectos formais, desenha-se como signo de ruptura com a tradiçāo e com os modelos de seus mestres e profissionais para quem trabalhara, Ramos de Azevedo e Tamburini. Dubugras era jovem, realizava seus primeiros trabalhos e neles buscava imprimir sua marca com uma linguagem pessoal e moderna.

Mesmo nos projetos baseados no do Grupo Escolar de Campinas, além das variaçōes formais e estilísticas. experimentou tímidas variaçōes espaciais. Estava em gestação o criador inquieto que transpareceria mais tarde em seus projetos da Estaçāo de Mairinque, e os ligados às tendências Art-nouveau e Neocoloniais.

Foi aí, na experiência de projeto, na pesquisa de soluçōes, que Dubugras teve sua participação mais substantiva, no início de sua carreira em São Paulo. Contribuiu criando, em um momento em que a variação de detalhes ainda era permitida e até incentivada dentro do serviço público.

Mais tarde, ainda nos projetos de escolas experimentou ainda mais variações, desenhando prédios onde inclusive as plantas e as opções de circulação variavam com bastante liberdade. São projetos em cujos desenhos percebe-se o entusiasmo do arquiteto pelo trabalho proposto, nos quais busca soluçōes inteiramente novas.

Suas pesquisas arquitetônicas, porém, e os vôos de liberação que tentou levantar em relação aos volumes criados pelo esquema do bloco contido de oito salas de aula divididas em dois pavimentos de planta rebatida nāo foi bem recebido. Por significarem custos maiores do que a solução inicial foram sumariamente adaptados por outros profissionais com alteraçōes radicais em suas concepções espaciais e formais.

De fato, como ocorreu nestes primeiros projetos adaptados por outros arquitetos que nāo o seu criador, a arquitetura escolar foi em alguns momentos fruto de adaptaçōes e somatórias de soluçōes já desenvolvidas anteriormente. Nesta fase inicial de pesquisa e experimentação pelo modelo ideal de prédio escolar, a colagem de aspectos já resolvidos foi procedimento empregado na superintendência, nem sempre com os melhores resultados.

Por outro lado, começava a ser idealizado o procedimento de padronização dos projetos em soluçōes-tipo. Foi Dubugras que introduziu o recurso de concepçāo de escolas em série, que se consagrou posteriormente: começou a utilizar seus projetos como modelos absolutamente repetíveis para mais de uma situação. O esquema, foi levado às últimas conseqüências no séc. $X X$, mas se esboçou com Dubugras em 1895 e 1896.

Do ponto de vista da intenção plástıca de suas composições Victor Dubugras em seus primeiros trabalhos, introduziu elementos da arquitetura historicista neogótica e neo-românica, nāo apenas nos projetos de escolas, mas também nos de fóruns e cadeias. Projetou com o espírito de modernizaçāo, ou ao menos contraposiçāo que esses estilos internacionalmente significaram em termos de superação do Ecletismo acadêmico da École des Beaux Arts. Seu gesto, quase rebelde em relação aos de seus mestres, porém, permanecerá isolado, prevalecendo por muito tempo nas construçōes públicas, soluções 
plásticas que vão abastardando e simplificando o vocabulário ornamental e compositivo do neoclássico.

Essa opção de Dubugras por criações filiadas ao que se convencionou chamar estilo neogótico apontam para uma característica de seu proceder profissional - um arquiteto sempre atento às tendências estilísticas. Enquanto, no final do séc. XIX, Dubugras projetava obras públicas em Sāo Paulo, o medievalismo estava ainda exercendo suas influências na arquitetura européla.

Posteriormente, ele próprio não permanecerá fiel aos estilos medievalistas. traçando com sua obra uma trajetória sempre marcada por uma intensa busca formal. Passando, mais tarde, pelas formas florais, conclui sua carreira como expoente do estilo neocolonial, com uma produção arquitetônica bastante particular, que ele chama arquitetura tradicional brasileira.

Pelo que foi dito até agora seria possivel dizer que somam argumentos em favor da crítica negativa que tradicionalmente se exerce sobre o Ecletismo cópias e excessiva preocupaçāo formal. O que a própria obra de Dubugras parece ensinar, porém, é que é a experimentação que traz a possibilidade dos saltos qualitativos. Mas, sobretudo, que ela deve ser analisada nos detalhes de seu próprio processo evolutivo, e não com um olhar à distância, condicionado pelos modos de projetar entronizados pela arquitetura moderna.

\section{José van Humbeeck / O Fim da Primeira Fase e a Afirmação de Modelos}

Enquanto profissionais como Ramos de Azevedo e Victor Dubugras se retiravam da tarefa de projetar escolas em São Paulo, depois de praticamente estabelecerem suas características fundamentais, começa a despontar na realização de projetos públicos o arquiteto José Van Humbeeck. Um arquiteto que, também dos quadros da Superintendência, assinará a partir do séc. XX um grande número de soluçōes para prédios escolares.

Humbeeck já vinha prestando serviços à superintendência desde sua contratação como desenhista em 1896. No início, limitara-se a projetar instalaçōes complementares (galpōes de abrigo, muros, sanitários, etc.) dos projetos realizados por outros, mas aos poucos vai recebendo maiores incumbências.

Além de sua prolongada permanência no serviço público José van Humbeeck não deixou outros traços na arquitetura paulista. Quem era, onde estudou e qual sua nacionalidade são algumas das questões que seu nome deixa sem respostas. É um arquiteto completamente desconhecido sobre o qual não se conserva sequer o prontuário funcional. como de resto de nenhum funcionário antigo da Secretaria de Obras.

Foram de sua responsabilidade dois passos importantes da arquitetura das escolas paulistas. Conquistas mais significativas do ponto de vista das etapas de realização e concepção dos projetos, do que propriamente grandes avanços arquitetônicos. Foi Humbeeck quem aperfeiçoou as técnicas de representação gráfica para utilização extensiva de projetos padronizados a partir do que as pranchas de desenhos de projetos idênticos sequer eram redesenhadas.

Além disto, desenvolveu em 1901, o primeiro projeto de prédio escolar térreo, a partir do que raramente construíram-se prédios de dois pavimentos fora da capital. Para conceber plasticamente este projeto inspirou-se no projeto de dois pavimentos, já realizado por Ramos de Azevedo, do qual utilizou parcialmente a fachada, mas inovou na solução espacial por esta organizar-se em torno de um patio. 


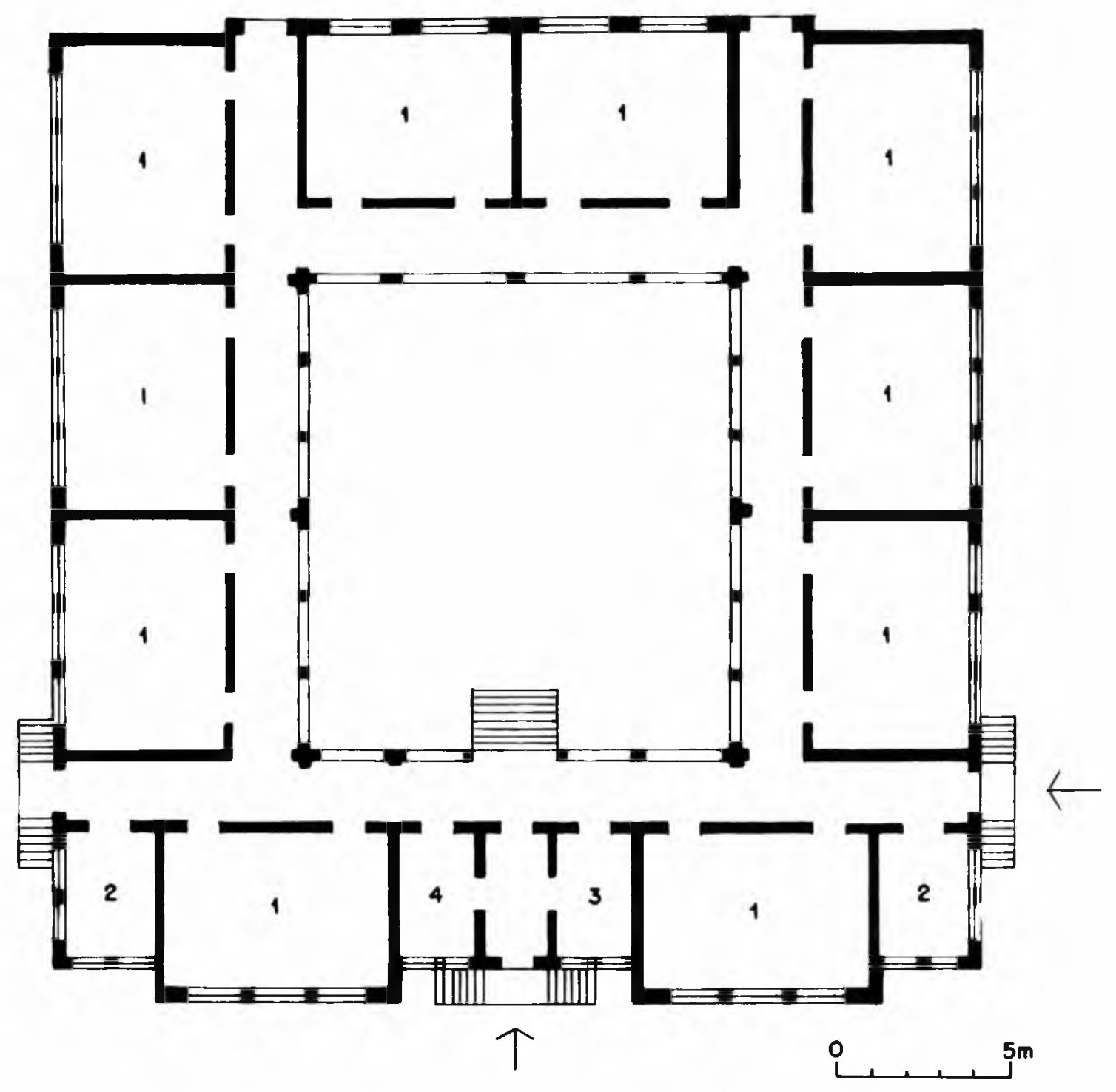

LEGENDA / USO ORIGINAL

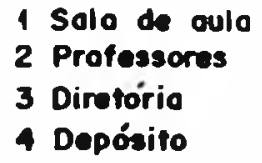

Até então os grupos escolares haviam se concentrado em prédios de volumes contidos, com dois pavimentos. Neles as salas se voltavam para um corredor central pouco iluminado. A solução em torno de um pátio trouxe luz e ventilação natural para as circulações. Pela primeira vez também se propunha a separação dos meninos e das meninas, através de alas simétricas. A partir de então as escolas do interior foram térreas, simétricas e tiveram circulações abertas. É sobre este passo inicial de Humbeeck, ainda tímido, que Manuel Sabater estrutura uma proposta de muita riqueza arquitetônica em 1909.

No início da década de 1910, quando ocorreu a grande produção de prédios escolares já referida, Humbeeck ainda estava trabalhando na repartição de obras públicas. Foi um arquiteto que não assinou projetos de prédios grandiosos ou muito criativos. Seu nome associa-se à arquitetura escolar, não por gestos geniais, por criaçōes plásticas marcantes. A estética de seus projetos foi tornando-se, especialmente nos projetos térreos que desenvolveu, pouco imaginativa; talvez correta, mas efetivamente sem brilho.

Sua contribuição, no entanto, se faz por seu trabalho como profissional de atuação longeva e dedicada. Humbeeck já estava presente quando Victor 
Dubugras experimentava no séc. XIX, e também quando novos profissionais inovaram nos anos 10, participando muito ativamente da grande produção desse momento. Durante esse período ele debruçou-se sobre sua mesa de trabalho e estudou com afinco a arquitetura necessária para as escolas paulistas. Propôs idéias simples e exeqüiveis, para cuja concepção olhou com muita atenção para os passos já realizados por seus colegas.

Desta forma foi o transmissor da experiência e até o responsável por momentos de inflexão e mudança na trajetória da arquitetura escolar paulista, como o da introduçāo dos pátios nos prédios térreos. Não foi genial, não se destacou, não transpôs os limites de atuação de um obscuro funcionário público. Mas, trabalho e conhecimento nāo se produzem apenas com grandes feitos e José van Humbeeck. esse anônimo arquiteto da repartição de obras é uma personagem cuja participação é inquestionável na história da arquitetura escolar paulista.

\section{Manuel Sabater e a Articulação dos Volumes}

Manuel Sabater, por sua vez, teve uma passagem breve, mas marcante pelo serviço público - o seu nome liga-se a projetos de escolas no período entre 1908 e 1911. Nesse período foi responsável por grande número de projetos arquitetônicos de escolas, nos quais imprimiu uma marca pessoal forte. Sabater propôs soluções de articulação de espaço criativas e de concepção formal elaboradas.

Manuel Sabater sobre quem nāo se conhecem dados pessoais, como a confirmação de sua provável nacionalidade espanhola ou sua formação profissional, tinha domínio da composiçāo dos espaços e dos recursos plásticos. Participou de um momento de transformaçāo e de muita qualidade na trajetória da arquitetura escolar paulista. Em sua obra destacam-se, sobretudo, projetos de grandes edifícios para grupos escolares na capital e no interior do estado.

Mas com certeza o que o qualificou para a responsabilidade de projetar esses grandes prédios foram seus projetos iniciais, como o aperfeiçoamento da soluçāo térrea em torno de um pátio proposta por Humbeeck. Inspira-se naquela solução anterior, mas para a composição de volumes e detalhes formais segue trajetória própria.

No primeiro projeto de escola que concebeu e que fora utilizado em duas localidades encontram-se já aspectos que marcarāo sua obra: a minúcia do detalhe, o controle compositıvo e a articulação de volumes com movimento. Sua contribuição teve um caráter inovador após os volumes rígidos das escolas em dois pavimentos e as experiênclas formalmente multo pobres como a do projeto tipo térreo de autoria de Humbeeck.

Aonde Humbeeck havia improvisado. Sabater comparece com um controle de quem conhecia composição. Seus espaços são mais equilibrados - suas salas de aula têm dimensōes homogêneas e se organizam através de eixos precisos. Mas aperfeiçoa o projeto, principalmente, ao desprender-se da rigidez de uma planta quadrada de fachadas de superfícies planas, e introduzir movimento nos volumes.

Sabater criou em relação ao alinhamento frontal uma alternância de recuos e avanços, ou seja, trechos de sombra e trechos salientes. É no detalhamento da fachada principal que o preciosismo de Sabater se manifesta ainda mais. O arquiteto propõe texturas e explora as possibilidades de desenho dos caixilhos. Em seu apego à minúcia esboça, em escala ampliada, o módulo básico de sua composição. Esta consistia em uma alternância de cheios e vazios. Os vazios eram as janelas, cujos desenhos dos caixilhos de madeira equilibravam linhas 


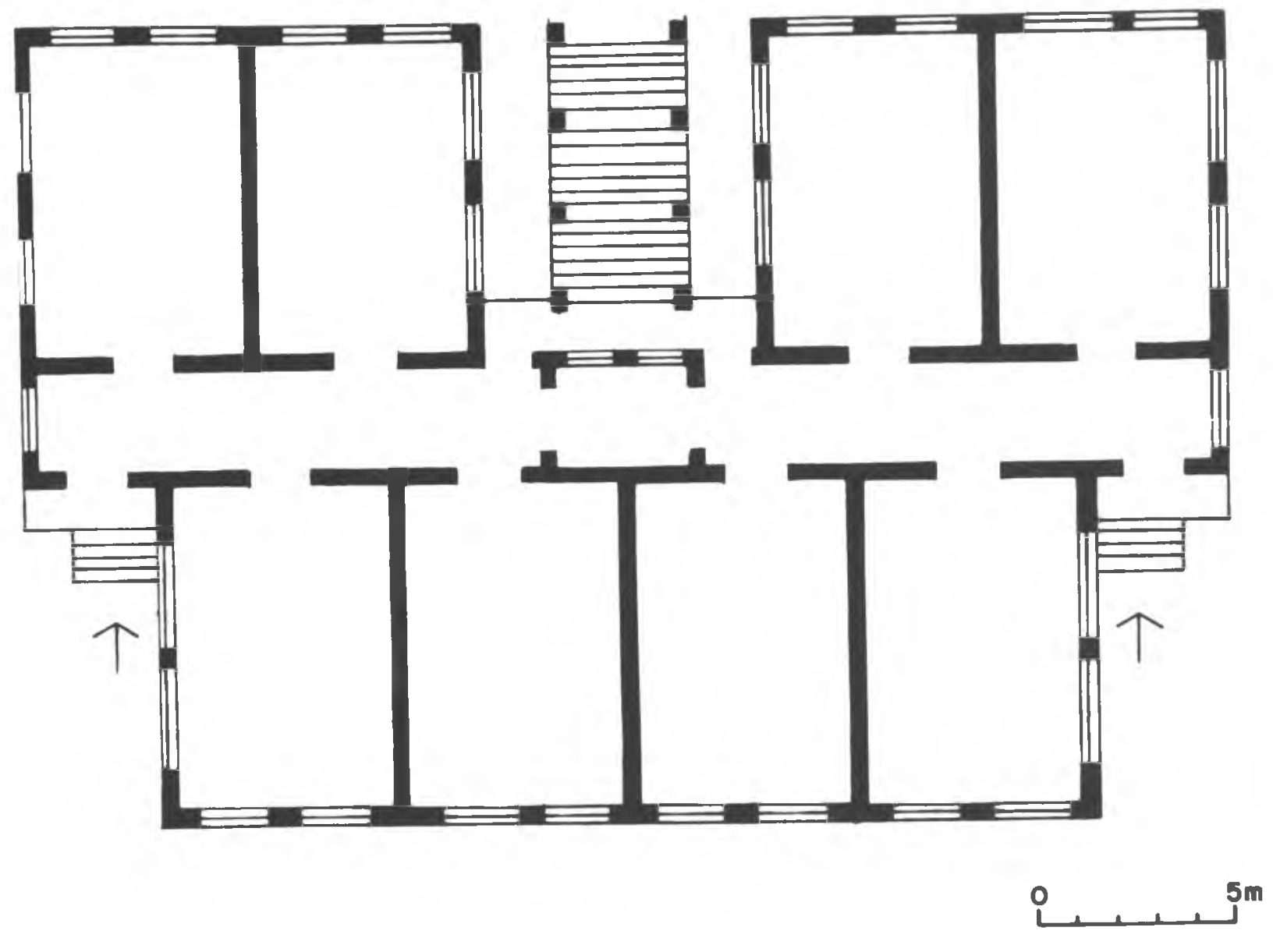

predominantemente verticais com pequenos segmentos quadrados nas extremidades. Os cheios eram trechos cuja ornamentação emoldurava as janelas e nos quais inseriam-se rasgos imitando tijolos aparentes.

Sabater é um arquiteto em cuja obra transparece um domínio do desenho, das normas compositivas acadêmicas, mas também uma liberdade de organização da linguagem e do repertório formal que delas se derivam, muito própria à sua época. Manuel Sabater é, sem dúvida, um arquiteto eclético e seus projetos apresentam uma linguagem plástica de um léxico heterogêneo. Mas é um arquiteto que se destaca pela forma como soube dispor com harmonia e expressividade o repertório formal acadêmico.

Sabater, em sua curta passagem pelo serviço público, realizou uma obra notável, que extrapola os limites das muitas criaçōes que ele próprio assina. Foi um daqueles autores cujas realizaçōes permanecem influenciando as que a elas se seguem.

Trabalharam com ele em 1911 e permaneceram à testa de outros fundamentais projetos da. arquitetura escolar paulista, dentre outros profissionais, o alemão Carlos Riosencrantz cuja participação cabe destacar.

\section{Carlos Rosencrantz e a Monumentalidade}

Rosencrantz realizou relativamente poucos projetos, mas entre eles figuram algumas das mais destacadas composiçōes da arquitetura escolar paulista. Carlos Rosencrantz, alemão, naturalizado brasileiro, foi criado em São Paulo, mas realizou seus estudos profissionais em Hamburgo na Alemanha. Trabalhou no serviço público até sua aposentadoria e consta que projetou também obras particulares que ainda carecem de identificação.

A arquitetura segura, os desenhos primorosos que realizava, e a caligrafia de Rosencrantz denotam uma identidade única, que trouxe uma injeção de origi-
Foto 4

Grupo Escolar de Dourado

Foto: fornecida pela autora

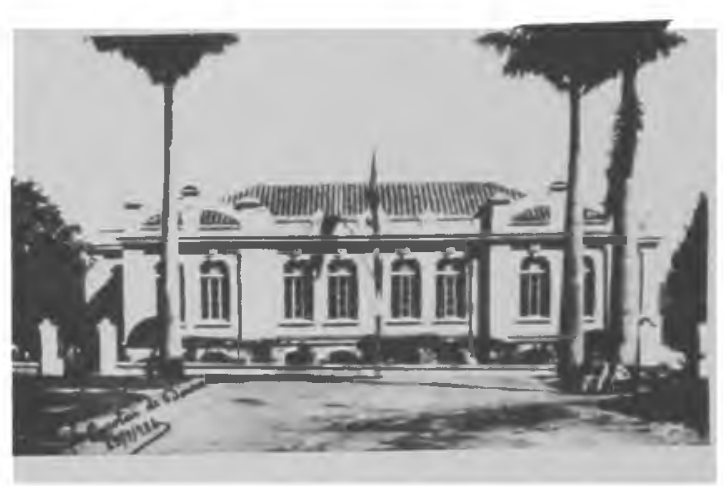


(3) Sobre a introduçăo do Ant Nouveau em Sáo Paulo ct. Catálogo da Exposiçăo Vila Penteado. FAUUSP/ Secretaria de Ciência e Tecnologia, 1976 e Silvia Ferreira Santos WOLFF, Walter PIRES, Vila Penteado/faU: trajeto de uma casa paulistana. Relatório de pesquisa elaborado para a Coordenadoria do Patrimonnio Cultural da Reitoria da USP, 1989

Foto 5

Grupo Escolar de São Carlos

Foto: fornecida pela autora nalidade aos projetos das escolas públicas paulistas. E é aí, no tratamento plástico, que o arquiteto mostra as peculiaridades de sua obra. Menos de dez anos após a introdução por Carlos Ekman do estilo "sezession" em Sāo Paulo, na vila da família Penteado em Higienópolis, construída em $1902^{3}$, Rosencrantz propôs um prédio público com esse estilo, o Grupo Escolar do Carmo. É certo que o grupo escolar tem uma composição mais ascética, de volumes mais restritos que sua antecessora, mas são de filiação "sezession" o seu conjunto, alguns detalhes e as linhas de acentuada verticalidade de suas envazaduras.

Nesse período Rosencrantz ainda era contratado como desenhista e nem sempre sua contribuição na arquitetura escolar está devidamente expressa. É
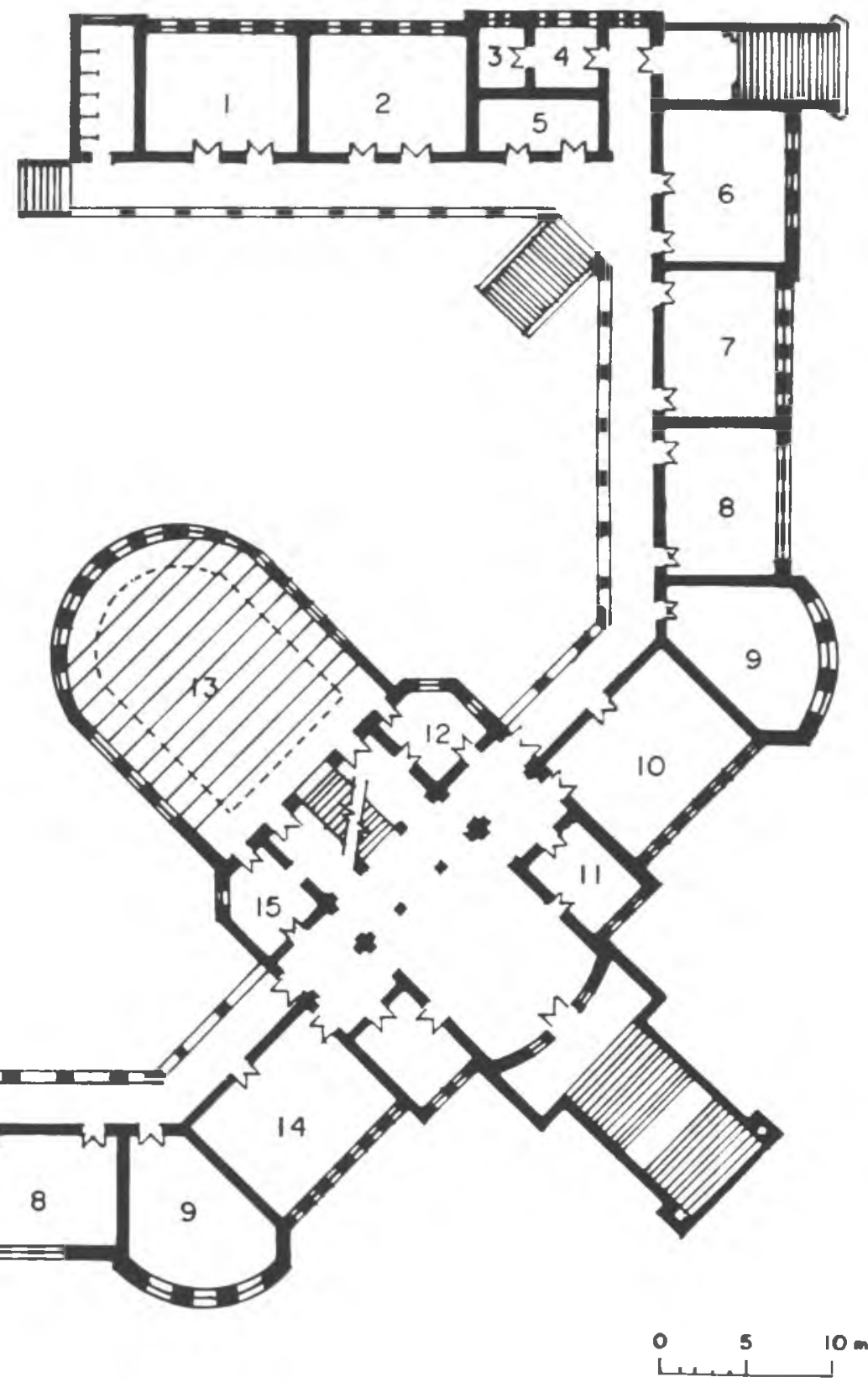

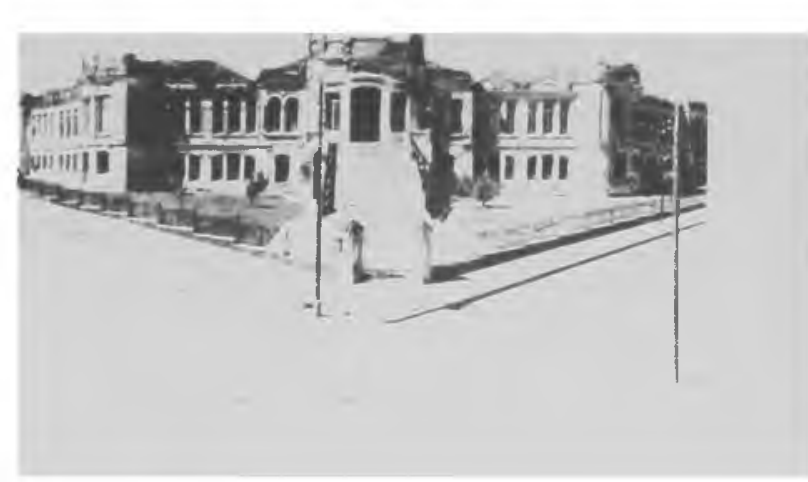

Pos - R. Prog. Pós-Grad. Arquit. Urb. FAUUSP, Sáo Paulo n.4 p. 91-106 dez. 1993
I. SALA DE HISTOKIA NATURAL

2. SALA DO 4 ANO

3. MATERIAL

4. BEDÉlS

5. VESTIÁRIO

6. SALA DO 30 ANO

7. SALA DO 22 ANO

8. SALA DO I: ANO
9. SALA de costura e pRENDAS
10. BIBLIOTECA
II. SALA DO SECRETÁRIO
12. SALA DO DIRETOR
13. SALA DA CONGREgAÇÃo E ANFITEATRO
14. SALA DE QUIMICA
15. SALA DOS PROFESSORES
16. SALA DE PSICOLOGIA EXPERIMENTAL 
o caso desse projeto, assinado por Achilles Nacarato. Sua participação, também, caracterizou-se por sua colaboraçāo em outros tantos projetos, principalmente em detalhes de desenhos elaborados. Inúmeras escolas apresentam detalhamento de serralheria, realizados por Rosencrantz em seu estilo pessoal, forte e seguro, nem sempre consoante com o partido plástico de seus colegas.

Rosencrantz, que já demonstrara seus méritos em projetos de grandes grupos escolares na Capital, esteve ligado ainda aos prédios de quatro escolas normais - os projetos de escolas públicas de maior monumentalidade em toda a Primeira República. Participou ora detalhando cômodos funcionais e esteticamente importantes como os auditórios nos prédios gêmeos de Botucatu e Piracicaba, ora participando das concepções arquitetônicas magistrais de Pirassununga e São Carlos.

Em Pirassununga a monumentalidade da arquitetura do prédio é acentuada pela linhas verticais predominantes da composiçāo. Estas linhas estabelecemse através de um controlado equacionamento das proporções e relaçōes entre as envazaduras e o espaçamento entre elas. São segmentos de pequena largura e desenho alongado. A verticalidade enfatiza-se com os panos de fachadas entre as janelas, estendendo-se desde a linha dos embasamentos até às platibandas, funcionando quase como colunatas, nas quais os intercolúnios sāo as próprias janelas.

Este efeito é especialmente trabalhado nas duas extremidades do conjunto que se projetavam em relaçāo ao terço central da fachada principal. Contribuíam para a força expressiva dessa fachada um conteúdo dinâmico estabelecido pelas linhas curvas das platibandas e desses dois volumes extremos, que se projetam em forma ligeiramente abaulada.

Ascendia-se ao terço central recuado através de escadaria. Esta, organizada com patamares intermediários e com grande monumentalidade, vencia o grande desnivel entre a cota da rua e o da entrada do prédio. Havia muitos outros acessos para a escola, mas a caracterização dessa como a principal era evidente e intencional.

A sábia associação da implantação do prédio no terreno e do uso de escadarias como recurso enfático também foi empregada por Rosencrantz no prédio da Escola Normal de São Carlos. Neste caso não são as linhas verticais que constróem a escala grandiosa do edificio - o prédio nem ao menos tem dois pavimentos, além do porāo, como as demais Escolas Normais. O efeito quase cenográfico de sua monumentalidade é obtido de outra forma.

Rosencrantz recupera a intençāo de um projeto de Victor Dubugras, não realizado no final do séc. XIX e implanta o prédio com seu acesso central no eixo de simetria entre duas alas. fazendo-o coincidir com a bissetriz do ângulo formado pela esquina de duas ruas. As alas sımétricas do edificio. em São Carlos, assentam-se ao longo do alinhamento do terreno, após estabelecerem uma testada principal perpendicular à linha que as divide. Essa testada, naturalmente afastada dos limites da esquina, favorece a formaçāo de um jardim fronteiro. Da mesma forma é guarnecido com um jardim posterior delimitado pela área semicerrada, quase um pátio que se forma através dos "braços" da planta.

A planta de São Carlos resultou forma pouco usual. Seus braços articulados movimentavam-se em relaçāo ao alinhamento de cada um de seus segmentos, com ligeiros avanços, recuos e espaços semicirculares. como os das extremidades abauladas da fachada principal de Pirassununga. 
Rosencrantz destaca-se assim como um criador que, não apenas utilizava com finalidade decorativa os recursos técnicos e materiais de que dispunha a construçāo civil da época, como também controlava com sabedoria as possibilidades de criar volumes ricos e imponentes.

\section{Escolas Paulistas e Criatividade}

A arquitetura escolar forjada sob a égide do poder público paulista ao longo da Primeira República tem inequivocamente feições específicas ligadas à cultura eclética e só teve transformações substanciais quando novo impulso de renovação das manifestaçōes artísticas do país ocorreu de forma expressiva, a partir dos anos 30 .

Verifica-se que, em muitos momentos desse longo período, o ideal de um único modelo de arquitetura escolar perfeito, irretocável e passivel de ser repetido em todas as localidades a um mínimo custo, foi meta desejada. Sempre em movimento, contudo, as soluções modificaram-se para atender a uma ou outra exigência do programa que até então nāo fora adequadamente resolvida; a uma diminuição dos custos; a minorar os esforços de projeto e, last but not least, às particularidades criativas de seus arquitetos.

A consolidação das formas de enfrentar e atingir esses objetivos se deu através de um processo evolutivo. Nesse processo houve os que contribuíram dando passos importantes nessa trajetória, profissionais que criaram escolas com disposiçāo espacial para tal, mas, sobretudo, com aparência do que ainda hoje reconhece-se como escolas. São arquitetos que nos ensinaram a decodificar os prédios públicos de acordo com seu uso e nos ensinaram muito mais a harmonia das composições e a sensaçāo dos espaços claros, amplos e arejados.

Esta arquitetura oficial destacou-se da arquitetura civil contemporânea, trazendo uma aura de novidade e funcionando como divulgadora de novos padrões estéticos e culturais. Os realizadores dessa arquitetura, quando iniciaram sua obra, buscaram inspiração, olharam a seu redor e para fora. Nāo lhes faltaram referências. A adaptação de modelos não era, contudo, subserviente e impensada. Havia que se criar uma arquitetura, conforme as modas internacionais sim, mas de acordo com as necessidades locais.

Afora isso havia as condições distintas de clima, iluminação e ventilação para as quais os profissionais, paulatinamente formados pela escola de engenharia local, ficaram atentos. Os arquitetos das primeiras escolas paulistas, homens de seu tempo, num país que buscava equiparar-se ao mundo cosmopolita. não foram refratárıos às influências da produção estrangeira. Nāo tinham como nem por que fazè-lo. mas tampouco imitavam-na de costas para seu próprio país.

As experiências anteriores funcionaram como referências, como tipos ideais para seus processos de criação. Não resultou um modelo único para todas as escolas, mas a arquitetura escolar paulista é uma arquitetura que não raras vezes se reproduz a partir de protótipos. É possivel que as escolas, enquanto tipologia funcional, não tenham criado formas inéditas, revolucionárias, mas são fruto de muito trabalho. São produto de atos criativos de homens que por ela muito se empenharam, documentos de um tempo, espaços que abrigaram tantas geraçōes de aprendizes. Sāo suportes de conteúdos simbólicos, arquitetura. 